\title{
DERLEME/ REVIEW
}

\section{DOĞUM SONU MUAYENEDE FARKINDALIK: DİASTAZİS REKTİ VE BAKIMI*}

\author{
Yeliz ÇAKIR KOÇAK** Habibe BAY*** Hafize ÖZTÜRK CAN****
}

\begin{tabular}{ccc}
\hline Alınış Tarihi/Received & Kabul Tarihi/Accepted & Yayın Tarihi/Published \\
11.09 .2018 & 17.05 .2020 & 30.06 .2020 \\
\hline Bu makaleye atıfta bulunmak için/To cite this article: & \\
Çakır Koçak Y, Bay H, Öztürk Can H. Doğum sonu muayenede farkındalık: diastazis rekti ve bakımı. \\
Anadolu Hemşirelik ve Sağlık Bilimleri Dergisi, 2020; 23(2): 304-310. DOI: 10.17049 /ataunihem.458866 \\
\hline
\end{tabular}

$\ddot{O} Z$

Diastazis Rekti, karın bölgesinin sol ve sağ ön yüzeyini tutan rektus abdominis kasları arasında ayrılma ve üst orta hat karında yaygın bir çıkıntı ile karakterize bir bozukluktur. Tanısı sağlık profesyonelleri (fizyoterapist, ebe, hemşire ya da doktor gibi) tarafindan konulabilir. Ĕger, sağllk profesyoneli bu durumdan şüphe ediyorsa fizyoterapi konsültasyonu isteyebilir. Diastazis Rekti, umbilikusun üstünde $4.5 \mathrm{~cm}$ ve altında $4.5 \mathrm{~cm}$ uzunluğunda (bazı kaynaklara göre $3 \mathrm{~cm}$ ), genişliği $\geq 2 \mathrm{~cm} /$ parmak olarak palpe edilebilir. Uluslararası literatürde Diastazis Rekti'nin, gebelik döneminde \%30-70, doğum sonu 6-8. haftalarda \%52.4 ve 6. ayda \%39.3 oranında görüldü̈̆̈̈ belirtilmektedir. Türkiye'deki prevelansı gebelerde \%24-55 olarak saptanmıştır. Diastazis Rekti gelişmesinde pek çok faktörün yanında özellikle gebeliğe bağlı ortaya çıkan hormonal değişiklikler, ileri anne yaşı, multiparite, sezaryen, büyüyen uterus ve uterusun fazla gerildiği durumlar ile buna bağlı artan intra-abdominal basınç etkilidir. Diastazi Rekti yaşam kalitesini düşürmektedir. Sağlık çalışanları doğum sonu muayene sırasında Diastazis Rekti saptar ise, solunum egzersizi, kegel egzersizi, pelvik-tilt, korse ya da abdominal bant kullanımı gibi koruyucu uygulamaları kadına öğretmeli, bunları uygulaması için motive edip izlemini yapmalıdır. Daha ciddi ayrılmalara ise farklı tedavi seçenekleri önerilmektedir. Bununla birlikte, doğum sonu bedenindeki değişimlerin takibi yanında yeni rol ve sorumluluklarına uyum sağlamaya çalışan kadının yaşam kalitesinin artması ve sağlıklı aile yapısının desteklenmesi için Diastazis Rekti önemlidir. Bu derleme ile, literatür sonuçlarına bağlı olarak Diastazis Rekti ve bakımı konusunda farkındalı̆ğn arttırılması amaçlanmaktadır.

Anahtar kelimeler: Bakım; diastazis rekti; doğum sonu muayene; rectus diastaz.

\begin{abstract}
Awareness on Postpartum Examination: Care of Diastasis Recti

Diastazis Rekti is a disorder characterized by separation between the rectus abdominis muscles holding the left and right anterior surface of the abdominal region and a widespread protrusion in the upper midline abdomen. The diagnosis can be made by a health professional (i.e a physiotherapist, midwife, nurse, or doctor). If the healthcare professional suspects this, they can request a physiotherapy consultation. Diastasis Rekti is defined as a palpated separation of $\geq 2$ fingerbreadths either $4.5 \mathrm{~cm}$ above, at or $4.5 \mathrm{~cm}$ below (according to some sources $3 \mathrm{~cm}$ ) the umbilicus. In the international literature, Diastasis Rekti was reported to be 30-70\% in pregnancy, 52.4\% at 6-8 weeks postpartum and 39.3\% during the 6th month after birth. In Turkey, the prevalence was $24-55 \%$ in pregnant women. In addition to many factors in the development of diastasis Rekti, especially hormonal changes that occur due to pregnancy, advanced maternal age, multiparity, cesarean, growing uterus and increased intra-abdominal pressure due to excessive stretching of the uterus are effective. Diastasia Rekti reduces quality of life. If health professionals detect Diastasis Rekti during postpartum examination, when the separation between the muscles is $3 \mathrm{~cm}$, they should teach the woman about protective practices such as breathing exercises, kegel exercise, pelvic-tilt, corset or abdominal band usage, and motivate and monitor them for application. Different treatment options are recommended for more serious separations. In addition to following the changes in the postpartum body, Diastazis Rekti is important for increasing the quality of life of the woman trying to adapt to her new roles and responsibilities and supporting the healthy family structure. In this study, it is aimed to raise awareness about Diastasis Recti and its care based on the results of the literature.
\end{abstract}

Keywords: Care; diastasis recti; postpartum examination; rectus diastasis

\footnotetext{
* Bu çalışma, 26-28 Nisan 2018 tarihleri arasında düzenlenen 1.Uluslararası İstanbul Ebelik Günleri’nde poster bildiri olarak sunulmuştur.

** Ege Üniversitesi Sağlık Bilimleri Fakültesi, Ebelik Bölümü (Arş. Gör. Dr.), ORCID ID: 0000-0002-86749092, e-posta: gulumseyc@gmail.com

*** Sorumlu Yazar: Selçuk Üniversitesi Sağlık Bilimleri Fakültesi, Ebelik Bölümü (Arş. Gör),ORCID ID: 0000-0001-5786-4385, e-posta: habibe.bay@ selcuk.edu.tr

**** Ege Üniversitesi Sağlık Bilimleri Fakültesi, Ebelik Bölümü (Doç. Dr.),ORCID ID:0000-0001-8213-3330, e-posta: hafizeztrk@gmail.com
} 


\section{GİRis}

Gebelik ve doğum sonu dönemde gebeye bakım veren sağlık profesyonellerinin; meme, abdomen ve fundus, loşia, perine, epizyotomi, alt ekstremiteler ve emosyonel yanıt gibi faktörleri değerlendirmesi temel sorumlulukları içindedir $(1,2,3) . \mathrm{Bu}$ değerlendirmeler sırasında yapılan abdominal muayene bütüncül ve bireyselleştirilmiş bakımın önemli bir parçasıdır. Diastazis Rekti Abdominis (DRA) değerlendirmesi ise, bu bakımın sadece bir yönüdür (4). DRA tanısı sağlık profesyoneli (fizyoterapist, ebe, hemşire ya da doktor gibi) tarafından konulabilir. Sağlik profesyonelleri, doğum sonu bakımda kanıt temelli uygulamalar doğrultusunda güncel bilgileri takip ederek ve bunlar1 mesleki uygulamalara entegre edilerek, DRA varlığından şüphe ediyorsa fizyoterapi konsültasyonu isteyebilir (5).

$\mathrm{Bu}$ bakış açısından yola çıkarak; gebelik nedeni ile görülebilen, abdominal muayene içinde yer almas1 gereken DRA'nın tanılanması, muayenesi ve komplikasyonların önlenmesi açısından konuya dikkat çekilmesi bu derlemenin amacını oluşturmaktadır.

\section{DRA Tanımı ve Görülme Sıklığı}

DRA literatürde farklı şekillerde tanımlanmış olsa da; "gebelik strasinda linea albada azalan gerilme direnci, karın duvarin saran rektus abdominis kaslarinin orta hatta ayrlmasi ve boşluk oluşmasıdır. Bu boşluk genellikle 'diastazis rekti' olarak adlandırllır" şeklindedir (6). Literatürde DRA'yı tanımlamak için, "Rektus Abdominis Diastasis (RAD)" veya "Rektus Abdominal Kasların Divarikasyonu (DRAM)" gibi terimlerle de karşılaşılmaktadır (7). Bu derlemede Diastazis Rekti Abdominis (DRA) şeklinde kullanılmıştır.

DRA, umbilikusun üstünde $4.5 \mathrm{~cm}$ ve altında $4.5 \mathrm{~cm}$ uzunluğunda, genişliği $\geq 2 \mathrm{~cm}$ (veya $\geq 2$ parmak) olarak palpe edilebilir $(8,9)$. Sheffield Teaching Hospitals (2017) ise, DRA uzunluğunu $3 \mathrm{~cm}$ olarak belirtmektedir (10). Genişliğin ölçüldügü alan 'inter-rekti' mesafesi olarak tanımlanmaktadır (11). DRA, umblikusun üstünde veya altında tek başına olabildiği gibi her iki bölgede birlikte de olabilir (Şekil 1) (5).

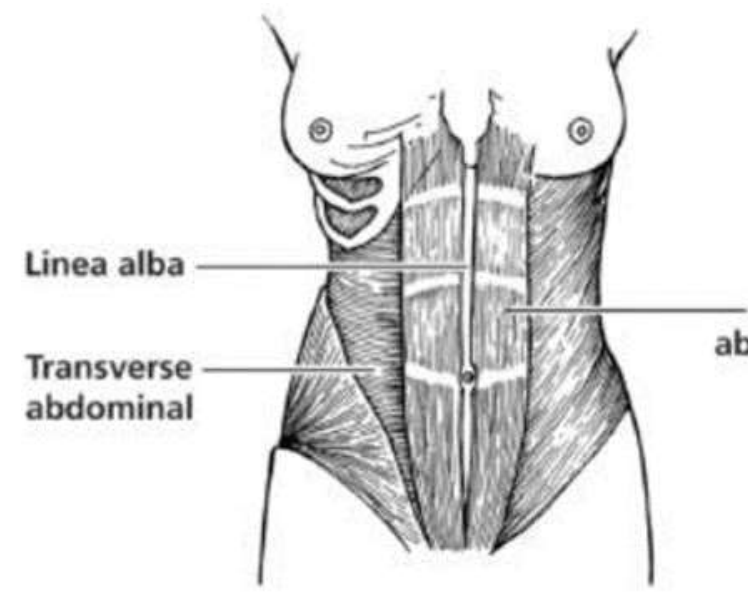

Gebelikten önce

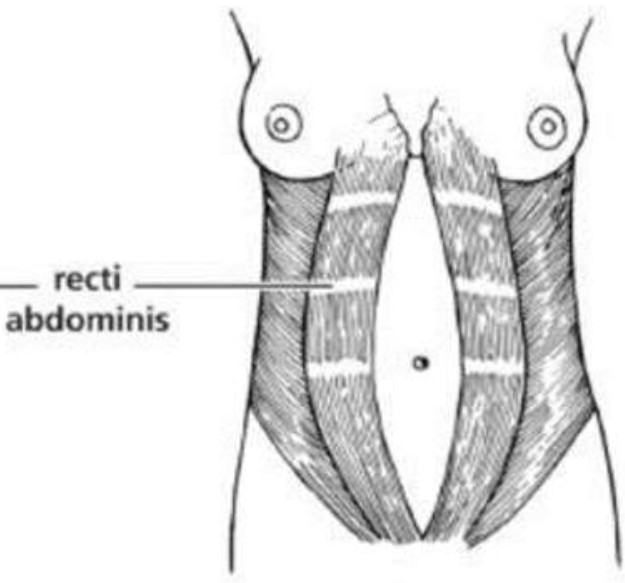

Doğumdan sonra

Şekil 1. Rektus Abdominis ve Diastazis Rekti

Norveç’te 300 primipar gebede yapılan bir çalışmada DRA'nın en fazla görüldüğü yerin umblikus olduğu belirtilmiştir. Bununla birlikte DRA prevalansının 21. gebelik haftasında \%33.1, doğumdan 6 hafta sonra $\% 60.0$, doğumdan 6 ay sonra $\% 45.5$ ve doğumdan 12 ay sonra $\% 32.6$ olduğu tespit edilmiştir (8). Amerika'da üreme çağındaki 71 primipar kadın arasında DRA prevalansını inceleyen başka bir çalışmada; doğum sonu 5. hafta ve 3 . ayda görülme oran1
\%36 olarak belirtmiştir (12). Benzer şekilde DRA'nın gebelik döneminde \%30-70 (5), doğum sonu 6-8. haftalarda $\% 52.4$ ve 6 . ayda $\% 39.3$ oranında görüldüğünü belirtilen farklı çalışmalar da bulunmaktadır (13). Türkiye'de DRA'ya ilişkin çok az çalışmaya ulaşılabilmiştir. Ankara'da bir doğumevinde gerçekleştirilen bir çalışmaya göre gebelerin \%55'inde DRA olduğu saptanmıştır (14). Türkiye'de genç multipar 
yetişkinlerde yapılan başka bir çalışmada ise DRA prevalans1 \%24.0 olarak tespit edilmiştir (15).

\section{Sorunlar}

DRA Risk Faktörleri ve Yol Açtığı

DRA her iki cinsiyette ve farklı yaş gruplarında ortaya çıkabilmektedir. DRA gelişmesinde; hızlı kilo kaybı veya obezite cerrahisi, daha önce geçirilmiş abdominal cerrahi ve genetik faktörler gibi pek çok faktörün etken olmasının yanında çoğunlukla gebelerde görülmektedir (5). Araştırmalar, inter-rekti mesafesinin gebeliğin yaklaşık 14. haftasından itibaren arttığını ve doğuma kadar da bu artışın devam ettiğini göstermektedir (11). Bunun nedeni; hormonal dalgalanma yani progesteron, östrojen ve relaksin miktarının yükselmesi ile beraber hedef dokularda ortaya çıkan gevşeme ve destekleyici konnektif dokuların fonksiyonunu yitirmesidir $(14,16)$. Bununla birlikte gebelik döneminde uterusun hacmi ve ağırlığının önemli derecede artması ve abdominal kaslar üzerine baskıda bulunması da abdominal fasianın gevşemesine neden olmaktadır $(14,16,17)$. Bu süreç DRA oluşumunu kaçınılmaz kılmaktadır. Aynı zamanda gebeliğin ilerlemesinin linea alba'nın bütünlüğünü etkilediği, bu nedenle DRA'in üçüncü trimester ve erken doğum sonu dönemde daha yaygın olduğu ileri sürülmektedir (18).

DRA oluşumunda açıklanan bu nedenlere ek olarak; sezaryen ile doğum, ileri anne yaşı, multiparite gebeliğe bağlı karın kaslarının zayıflaması, çoğul gebelik, polihidroamnios, makrozomik fetüs gibi uterusun fazla gerildiği durumlar $(19,20)$ ile buna bağlı artan intraabdominal basınç da DRA oluşumunda etkili olmaktadır $(5,19,20,21)$. Bu nedenlere zit olarak Portekiz'de 84 sağlıklı primipar kadının dâhil edildiği çalışmada gebelik öncesi vücut kitle indeksi, kilo alımı, bebeğin doğum ağırlığ 1 veya karın çevresi (13) gibi faktörlerin doğum sonu 6.ayda DRA oluşumunda etkili olmadığından bahsedilmektedir. Norveç'te 300 primipar kadında yapılan başka bir çalışmada ise; ağır kaldırma, çocuk taşıma ve düzenli egzersiz yapma ile DRA arasında ilişki olmadığı bildirilmiştir (8).

Karın duvarının gövde ve pelvik stabilite, solunum, gövde mobilizasyonu ve karın iç organlarının desteklenmesinde önemli işlevleri vardır. İnter-rekti mesafesindeki artış, bu işlevleri tehlikeye atar, karın kaslarını zayıflatabilir ve işlevlerini etkileyebilir. $\mathrm{Bu}$ durum, gövde mekaniği, bozulmuş pelvik stabilite ve postür değişiklikleri (omurga ve pelvisi yaralanmaya karşı daha savunmasız bırakan pozisyonlar) ile sonuçlanabilir (11). Ciddi DRA varlığında bel ağrıs1 gelişmesi söz konusu olduğu gibi fetüsün ve abdominal içeriğin de zarar görme riski vardır. Hatta DRA'ya bağlı olarak travay ve doğumda ortaya çıkabilen malprezantasyon ve etkin olmayan abdominal kontraksiyonların görülmesin de olas1 olduğu belirtilmektedir $(6,12,22)$.

\section{DRA Muayene Basamakları}

DRA, vücudun sirt bölgesinin daha fazla çalışmasına neden olmakta ve buna bağlı olarak ortaya çıkan ağrı bireylerin yaşam kalitesini düşürmektedir $(5,21)$. Lohusanın hem kendisi hem de fetüs ve yenidoğanın gebelik ve doğum sonu dönemi en sağlıklı şekilde tamamlamaları için kadının yaşam kalitesinin yüksek olması önemlidir. Kadına bakım veren sağlık çalışanlarının DRA'yı değerlendirerek gerekli durumlarda konsülte etmeleri önerilmektedir. DRA değerlendirmesi öncelikle sağlik profesyoneli tarafindan yapılmalıdır. Bunun için, sağl1k profesyoneli değerlendirme basamaklarını bilmeli ve uygulayabilmelidir (Resim 1). Bu uygulama basamakları aşağıda verilmiştir $(4,11,19)$.

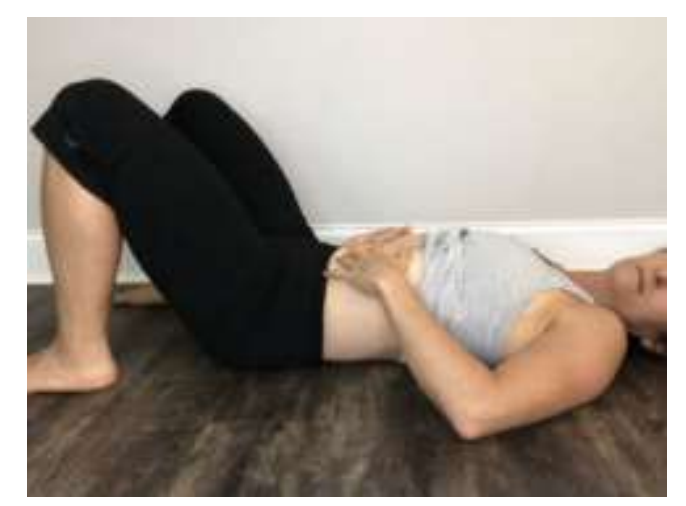

Resim 1. Kendi kendine DRA muayenesi

Muayene Pozisyonu: Kadın elleri yanlarında, başı yastıkla desteklenmiş, dizlere 2530 derecelik açı ile fleksiyon yaptırılarak rekümbent (sırtüstü) pozisyon alması için desteklenir. Abdominal kasların rahatlaması için bacakların gevşetilmesi istenir. Abdominal gevşeklik nedeni ile palpasyonda zorluk yaşanırsa kadından başını kaldırması istenir. Bu pozisyonda karın kasları kasılacağından DRA varlığı daha rahat değerlendirilebilir. Antenatal izlemlerde DRA değerlendirmesi yapıllyor ise gebenin uzun süreli sirt üstü pozisyonda kalmaması sağlanmalıdır. Gebede supin hipotansif bulgular takip edilmelidir (19). 


\section{DRA Elle Muayene Basamakları}

- Kadına muayenenin amacı açılanır, onay alınır.

- Mesanesinin boş olması sağlanır.

- Karnı açılır ve ellerin soğuk olmamasi sağlanır.

- Kadının mahremiyeti sağlanarak karın açık kalacak şeklinde üzeri örtülür.

- Umblikusun altından ve üstünden karın kasları parmak uçları ile palpe edilerek ayrılmanın olup olmadığı, eğer ayrılma mevcutsa ayrılmanın genişliği ve uzunluğu (inter-rekti mesafesi) araştırılır.

- İnter-rekti mesafesi umblikusun altından ve üstünden uzunluk ölçümü $(\mathrm{cm} /$ parmak genişliği) ile belirlenerek kaydedilir. Ayrılma düzeyinin mezura kullanılarak belirlenmesi ile objektif bir bulguya ulaşılabilir.

- Saptanan bulgular kadın ile paylaşılır.

- Elde edilen bulgular değerlendirir ve DRA varlığından şüphe ediliyorsa fizyoterapi konsültasyonu istenmelidir.

- Evde izlem yapma, tekrar kontrole gelme ya da doğum sonu karın egzersizleri konusunda kadına bilgilendirme yapılır.

- Bunun birlikte evde izlem için lohusa bilgilendirilerek, kendi kendine DRA muayenesinin nasıl yapılacağı kadının zamanında destek talep edebilmesi için ögretilebilir (Resim 2) (23).

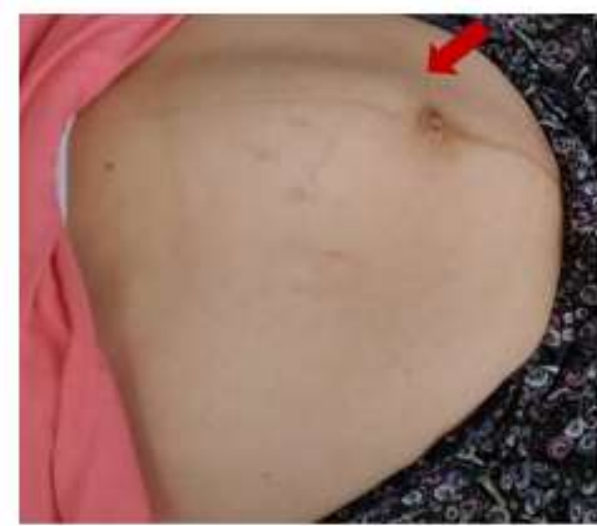

a) DRA görünümü

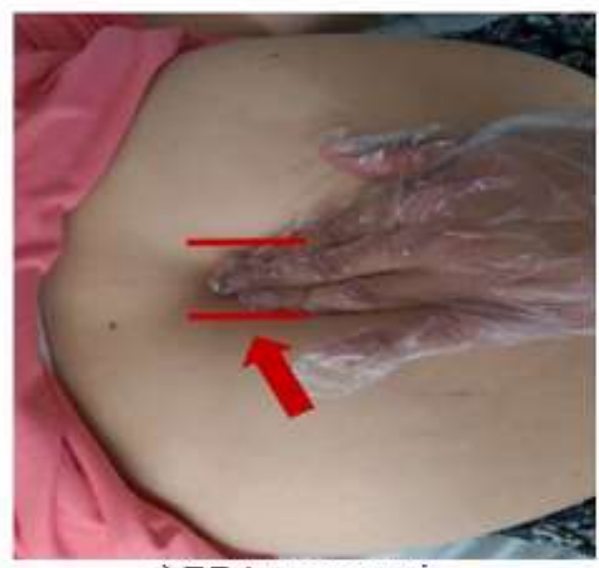

c) DRA muayenesi

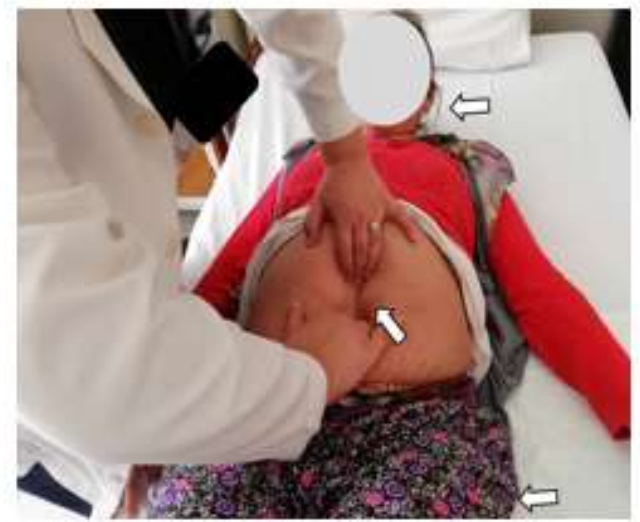

b) DRA elle hissedilmesi

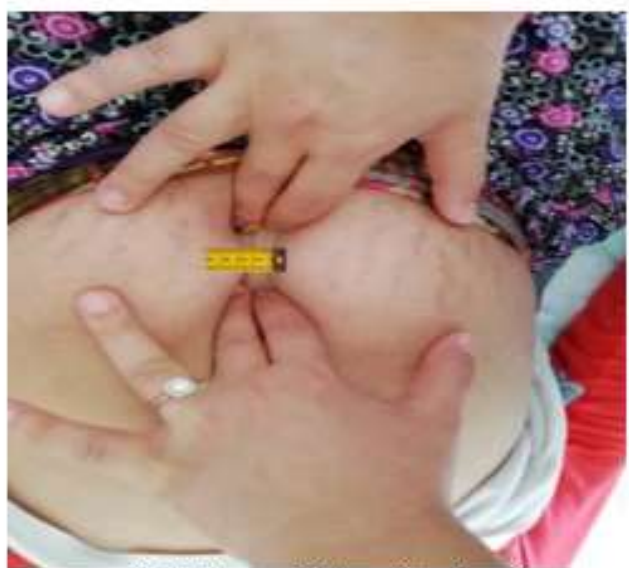

d) DRA açıklığın ölçülmesi

Resim 2. Doğum Sonu DRA Muayenesi, Doğum sonu 1. Gün (Yazarın kendi arşivinden, hastanın sözel olarak izni alınmıştır).

\section{DRA'nın Bakımı ve Yönetimi}

Sağlık profesyonelleri DRA varlığını değerlendirmek için teorik bilgiye sahip olmalı ve gerekli işlemleri uygulayabilmelidir. DRA bakım yönetimi; koruyucu yaklaşım, DRA tespiti ve bakım basamaklarını içermektedir. Bu nedenle gebelerin antenatal izlemleri ve muayenelerinde Leopold muayenesi sırasında DRA varlığ değerlendirilmelidir. Doğum sonu muayenesi yapılan kadının DRA oluşumunda Obstetrik kay- 
naklı nedenler dışındaki diğer faktörlerin de• belirlenmesi gereklidir (24).

DRA asemptomatiktir ve kendini genellikle doğum sonu ele verir (25). Sağlık çalışanları doğum sonu muayene sirasında DRA saptar ise, kadına solunum egzersizi, kegel egzersizi, pelviktilt, korse ya da abdominal bant kullanımı gibi koruyucu uygulamaları öğretmeli, bunları uygulaması için motive edip izlemini yapmalıdır $(4,5,10)$. Eğitim ve kilo kaybını içeren konservatif tedavi seçenekleri genellikle ilk basamak tedavi olarak önerilmektedir (26). Daha ciddi ayrılmalarda ise farklı tedavi seçenekleri (plikatür, abdominoplasti gibi cerrrahi tedaviler) önerilmektedir. Intra-abdominal basınç artışını azaltarak DRA gelişimini ya da artmasını engelleyebilecek aşağıdaki genel tavsiyeler ile kadına yardımcı olunabilir. Kadına verilecek tavsiyeler aşağıda özetlenmiştir $(4,5,10)$.

Gebelikte:

- Mekik çekmekten ve ağır kaldırmaktan kaçınılması,

- Öksürürken ve bağırırken abdominal gerginliğin artmasını önlemek için karnın el ile desteklenmesi,

- Bol miktarda su içerek ve yüksek lifli diyet yaparak kabızlıktan kaçınılması,

- Çocuk arabası veya alışveriş arabası iterken, merdiven kullanırken iyi bir vücut postürü sağlanması ve destek için göbeğin içine çekilmesi,

- Yatağa girip çıkarken dikkatle hareket edilmesi (yatağa yatarken ve yataktan kalkarken öncelikle yan dönme ve karnın altta kalan bölümünün el ile desteklenmesi) $(4,5,10)$.

Doğumda:

- Doğum sirasinda serbest hareket edebilmesi,

- Karın içi basıncını artıran ve glotisi (yani valsalva manevrasi) kapatan uygulamalardan kaçınılması,

- Sirtüstü doğum pozisyonları yerine sakrum serbestliğini öne çıkaran pozisyonların kullanılması,

- Müdahaleli doğum olasılığını azaltan uygulamaların desteklenmesi (27)

Doğumdan sonra:

- Karın içi basıncını azaltan statik ve dinamik duruşların tercih edilmesi (yani gevşemiş nötr bir omurganın korunmas1),

- Yüksek etkili egzersizlerden kaçınılması ve vücut mekaniğinin korunması,
Günlük görevler için optimum vücut mekaniği ve motor aktivasyon stratejilerinin teşvik edilmesi (bebek arabasını itmek, bebek taşımak) (27).

DRA muayenesi Rectus Abdominis kasının elle palpe edilerek, bu kasta ayrilma olup olmadığının değerlendirilmesi amacıyla yapılır. $\mathrm{Bu}$ izlemlerde kadınlar kas tonusunun çok iyi olmasını sağlayan abdominal kaslara odaklanmalıdır (11).

Sağlık profesyonelleri, muayene sirasında sorun saptanması durumunda çözüm odaklı bir yol izlemelidir. $\mathrm{Bu}$ nedenle DRA saptadığında, gebe ya da lohusa uzman desteği alması için fizyoterapiste yönlendirilmelidir. DRA doğum sonu dönemde tespit edilmiş ise bu süreçte kadına korse ya da abdominal bant kullanımı önerilebilir. Burada dikkat edilmesi gereken doğum sonu dönemde involüsyon süresi olan 6-8 hafta içinde uterus involüsyonunu olumsuz etkileyebilecek yaklaşımlardan uzak durulmasıdır (20).

Gebelik izlemi ve doğum sonu süreçte lohusayı takip etme ve bakım verme sorumluluğu olan ebe ve hemşireler, izlemlerde karın muayenesi sırasında mutlaka DRA varlı̆̆ını değerlendirmeli ve bunu kaydetmelidir. Doğum sonu lohusanın izlemi ve değerlendirilmesinde standardize edilmiş muayene basamakları için; BUBBLERS akronomi (Memeler-Breasts; Uterus; Mesane, boşaltım-Bladder; BarsaklarBowels; Loşia-Lochia; Epizyotomi; Emosyonel yanit-Emotional Response ve Human's bulgusuHuman's Sign) sağlık çalışanlarına rehber olmaktadır $(1,2)$. DRA muayenesinin de eklenmiş muayene şekli için BUBBLEHED kısaltması önerilmektedir (28). Ancak, Sağlık Bakanlığı tarafından hazırlanmış Doğum Sonu Bakım Yönetim Rehberi'nde (2018) DRA muayenesi yer almamaktadır (3).

\section{SONUÇ VE ÖNERILER}

DRA'nın ülkemizde görülme oranına ilişkin yeterli sayıda araştırma olmadığı var olan araştırmalarda ise yaygın olduğu görülmektedir. Doğum sonu bakım rolü olan sağlık profesyonellerinin DRA muayenesini rutin muayenelerine dâhil etmeleri gerekmektedir. Bununla birlikte DRA oluşumuna neden olan faktörlerin tüm sağlik profesyonellerince bilinmesi ve farkına varılması, gebelik izlem ve takiplerinde DRA'nın tanılanmasını sağlayacaktır. DRA tanılanması, erken dönemde takibi, bedenindeki değişimlerin yanında yeni rol ve sorumluluklarına uyum sağlamaya çalışan kadının yaşam kalitesinin artması ve sağlıklı aile yapısının desteklenmesi açısından da önemlidir. Tanılaması kolay bir muayene ile sağlanırken, 
tedavisi aşamasında da erken dönemde fark edilmesi ayrıca önemliydi.

Çıkar Çatışması: Yazarlar arasında çıkar çatışması bulunmamaktadır

\section{KAYNAKLAR}

1. World Health Organization. WHO recommendations on Postnatal care of the mother and newborn. October 2013. Erişim adresi https://www.healthynewbornnetwork.org/hnncontent/uploads/Postnatal_Care_Guidelines_web_ v2.pdf (Erişim tarihi 15.03.2020)

2. Eryılmaz HY. Doğum Sonu Değerlendirme: Bir Kontrol Çizelgesi Örneği. Hemşirelikte Eğitim ve Araştırma Dergisi 2009;6(1):20-6.

3. T.C. Sağlık Bakanlığı. Doğum Sonu Bakım Yönetim Rehberi. Halk Sağlığı Kurumu Kadın ve Üreme Sağlığı Daire Başkanlığı. 2018 Ankara, T.C. Sağlık Bakanlığı Yayın No: 925. Erişim Adresi: https://sbu.saglik.gov.tr/Ekutuphane/kitaplar/dsbyr _2.pdf (Erişim tarihi:01.02.2019).

4. Johnson R, Taylor W. Skills for Midwifery Practice 2nd ed. Edinbrugh: Churchill Livingstone 2002.

5. Boot Camp \& Military Fitness Institute. Diastasis Recti: An Overview 2015. Erişim Adresi: https://bootcampmilitaryfitnessinstitute.com/injury /diastasis-recti-an-overview/ (Erişim: 10 Mart 2019)

6. Mota P, Pascoal AG, Sancho F, Carita AI, Bø K. Reliability of The Inter-Rectus Distance Measured by Palpation. Comparison of Palpation and Ultrasound Measurements. Manual Therapy 2013;(13):294-8.

7. Michalska A, Rokita W, Wolder D, Pogorzelska J, Kaczmarczyk K. Diastasis Recti Abdominis - a Review of Treatment Methods, Ginekologia Polska 2018;89(2):97-101.

8. Sperstad JB, Tennfjord MK, Hilde G, EllströmEngh M, Bø K. Diastasis Recti Abdominis During Pregnancy and 12 Months After Childbirth: Prevalence, Risk Factors and Report of Lumbo Pelvic Pain. British Journal of Sports Medicine 2016;0:1-6.

9. Gluppe SL, Hilde G, Tennfjord MK, Engh ME, Bø K. Effect of a Postpartum Training Program on Prevalence of Diastasis Recti Abdominis in Postpartum Primiparous Women: A Randomized Controlled Trial. Physical Therapy 2018;98(4):260-8.

10. Sheffield Teaching Hospital. Diastasis of the Rectus Abdominus Muscle. Information for Patients MSK Outpatients - Women's Health (Therapy) 2017. Erişim adresi: https://publicdocuments.sth.nhs.uk/pil3525.pdf. (Erişim: 10 Mart 2018)

11. Benjamin DR, Van de Water ATM, Peiris C L. Effects of Exercise on Diastasis of the Rectus Abdominis Muscle in The Antenatal and Postnatal
Yazar Katkısı: Fikir, tasarım ve makalenin yazımı tüm yazarlar tarafından yapılmıştır.

Periods: A Systematic Review. Physiotherapy 2014;100(1):1-8.

12. Boissonnault JS, Blaschak MJ. Incidence of Diastasis Recti Abdominis During the Childbearing Year, Physical Therapy 1988;68(7):1082-6. https://doi.org/10.1093/ptj/68.7.1082.

13. Mota PGF, Pascoal AGBA, Ana Carita AIAD, Bø K. Prevalence and Risk Factors of Diastasis Recti Abdominis from Late Pregnancy to 6 Months Postpartum, and Relationship with Lumbo-Pelvic Pain. Manual Therapy 2015;(20):200-5.

14. Akbayrak T, Akarcalı İ, Çıtak İ, Kara F. Gebelikte Diastasis Recti Abdominis, Rectus Abdominus Kas Kuvveti ve Bel Ağrısı Arasındaki İlişki. Türkiye Klinikleri Jinekoloji Obstetrik Dergisi 2001;11:215-19.

15. Turan V, Colluoglu C, Turky1lmaz E, Korucuoglu U. Prevalence of Diastasis Recti Abdominis in The Population of Young Multiparous Adults in Turkey. Ginekologia Polska 2011;82;817-21.

16. Cunningham FG, Leveno KJ, Bloom SL, Spong CY, Dashe JS, Hoffman BL et al. Maternal Fizyoloji. Çeviri Edit: Yıldırım G, Türk VA, Ekiz A, Erol O. Williams Obstetrik 24. Edisyon, USA: The McGrow-Hill Companies, Nobel Tip Kitabevleri Tic. Ltd. Şti. 2016, 46-77.

17. Köseli D, Akın L. Lohusalık Dönemi ve Bakımı. Maternal-Fetal Tıp ve Perinatoloji Çalışma Grubu (e.d.) Beksaç MS, Demir N, Koç A (Koordinatörler). Obstetrik; Maternal-Fetal Tip ve Perinatoloji. Ankara: Medical Network-Nobel Tip Kitabevleri 2001; 1377-81.

18. Demartini E, Deon KC, Fonseca EGJ, Portela BS. Diastasis of the Rectus Abdominis Muscle Prevalence in Postpartum. Fisioter Mov 2016;29(2):279-86.

19. Yücel U. Abdominal Muayene ve Değerlendirme, 4. Bölüm: Doğum Sonu Dönem Değerlendirme ve Bakım. (Bölüm Edt.) Hafize Öztürk Can, Gamze Durmazoğlu. Ebelik Uygulama Standartları. (Edt.) Behzat Özkan, Esin Çeber Turfan, Serap Yaşaroğlu Toksoy. Ankara, Vize Basın Yayın, 1. Bask1 2016; 290-7.

20. Taşkın L. Doğum Sonu Dönem. Doğum ve Kadın Sağlı̆̆ 1 Hemşireliği (13.Baskı), Akademisyen Tıp Kitabevi, 2016: 533-71.

21. Emanuelsson P.Alternatives in the Treatment of Abdominal Rectus Muscle Diastasis: An Evaluation.[Doctoral thesis] Karolinska Universitetssjukhuset, Solna: Dept of Clinical Science, Intervention and Technology, 2014. Erişim adresi: https://openarchive.ki.se/xmlui/handle/10616/4224 5. (Erişim: 20 Mart, 2018). 
22. Beyaz AE, Özcan E. Gebelikte Görülen Kas-İskelet Sistemi Kaynaklı Ağrılar ve Tedavi Yaklaşımları. Türkiye Fiziksel Tıp ve Rehabilitasyon Dergisi 2005;51(2):65-8.

23. Johnson BP. Diastasis Recti: What You Really Need to Know. Erişim adresi: https://mamamadestrong.com/2019/07/16/diastasis -recti-what-you-really-need-to-know/ Erişim tarihi: 20.08.2019.

24. Aktan B. Klinik Pilates Egzersizleri ve Doğuma Hazırlık Eğitiminin Sadece Doğum Eğitimine Göre Doğum Sonuçları Üzerine Etkisi. Yayımlanmamış Doktora Tezi, 2015.

25. Sigdel M, Fernandez MA. Sudden Diastasis of Rectus Abdominis During Labor: A Case Report. Georgetown Medical Review 2019;3(1):1-5.
26. Olsson A, Kiwanuka O, Wilhelmsson S, Sandblom G, Stackelberg O. Cohort Study of the Effect of Surgical Repair of Symptomatic Diastasis Recti Abdominis on Abdominal Trunk Function and Quality of Life. British Journal of Surgery Open 2019; 3: 750-8.

27. Dufour S, Bernad S, Davis BM, Graham N. Establishing Expert-Based Recommendations for the Conservative Management of PregnancyRelated Diastasis Rectus Abdominis: A Delphi Consensus Study. Journal of Women's Health Physical Therapy 2019;43(2): 73-81.

28. BUBBLEHED Assessment Handout, Erişim Adresi:

http://my.ilstu.edu/ rhhudgi/31601/316/bubble he $\underline{\mathrm{ad} \% 20 \mathrm{wk} 4 . p d f}$ (Erişim: 10 Mart 2018) 